desy offers similar data faster and less expensivelys. The system is similar in accuracy to the best available terrestrial geodesy, but far surpasses it in ease of application and production rate. Yet in the developing nations geodesy remains poor or non-existent. The longer precise geodesy is delayed in such nations, the longer will be the delay in developing earthquake forecasts based on epicentral strain development. One step forward was the recent adoption by an ICSU subcommittee of a resolution that space geodesy should be applied to the characterization of seismic risk in the developing world.

Populations in some earthquake-prone regions will more than double within less than the time of one complete earthquake cycle. Space geodesy offers a method for long-term forecasting that will identify areas that are especially at risk, and in which stringent building regulations, especially for high-rise constructions, should be imposed and observed. No 'supercity' was affected in the Armenian disaster yet the death toll was enormous because of inadequate building practices. A combination of new technology and recognition of the centres of population especially at risk can help reduce the scale of such catastrophes in the future.

CIRES, University of Colorado,

Roger Bilham

\section{Boulder, Colorado 80309}

\section{USA}

1. Prospects of World Urbanization Revised 1984-5 (UN Dept Int. Econ. \& Soc. Affairs, 1987).

Nishenko, S.P. \& McCann, W.R. Maurice Ewing Serie Vol. 4, 20-28 (American Geophysical Union, 1981).

Rikitake, T. Earthquake Prediction (Elsevier, 1976)

4. Ambraseys, N.N. in Seismicity and Seismic Risk of the Offshore North Sea Area (eds Ritsema, A.R. \& Gur-
Orste pinar, A.) 317-345 (Reidel)

Bilham, R. in Aerospace Century XXI 1637-1659 (American Astronautical Society, 1988).

\title{
Trial of human malaria vaccine
}

SIR-I wish to raise an important point in connection with the report by Patarroyo et $a l$.' of the first human trial of a vaccine, which is composed of synthetic peptides, against the asexual blood stage of the malaria parasite, Plasmodium falciparum.

Patarroyo et al. evaluated humoral immune responses in their volunteers before immunization and challenge. For that they used both an ELISA test, taking an optical density of above 0.2 as positive, and an IIFA test, which was taken to be positive at titres above 1:20. By those criteria, 7 of the 13 volunteers were positive by one or both tests before immunization. In what way may the antibodies detected in these 7 volunteers have influenced the immune response to vaccination?

More important, why were the antibody-positive volunteers not excluded from the trial on the grounds that the presence of antibodies indicates past exposure to malaria? Malarial infection is very common in the Colombian military forces. Many blood donors at the Central Military Hospital are asymptomatic malaria carriers ${ }^{2}$ who are not aware of their past infection.

Those involved in malaria vaccine development should be very careful to design protocols adequate for evaluation, and take great care not to make over-optimistic claims based on preliminary results. Even if a vaccine becomes available, it would be some years before it could be integrated into the multiple approaches needed to control this complex disease.

Carlos A. Espinal Sociedad Colombiana de Parasitologia y Medicina Tropical, AA 100084, Unicentro Bogota, Colombia

SiR-Several points made by Patarroyo et $a l^{\prime}$. deserve more careful discussion.

First, the immunization protocols differed for the two different proteins. Ought the different protection results be attributed to the differences in proteins, vaccina- tion schedules or times before challenge? The authors do not comment on the fact that two doses of $\operatorname{Spf}(60) 30$ gave better protection than three.

Second, cross-reactivity in the humoral response to the two very different protein immunogens was detected in several vaccinees. If this is explained by a reaction against the linking peptide, as the authors propose, it would follow that there was almost no immune response against important epitopes in most vaccinees.

Third, the authors mention that very different results were obtained depending on whether acridine orange or Giemsa were used to determine parasitaemia. Which were reported?

National Institute of Health,

Moises Wasserman Avenida Eldorado con Carrera 50 , AA 80080, Bogota, Colombia

PATARROYO REPLIES-In response to the question of whether some of our volunteers had previously had malaria, we have now tested both by ELISA and IIFA the sera from 109 volunteers, all from nonendemic areas (which was one of our selection criteria) and who had never been in malarious areas. As with the volunteers in our vaccine study, about 10 per cent of the new sera had very low (less than 1:20) antibody titres by IIFA. This is accepted throughout the world as background level in this type of test. Malaria infection is common within the Colombian military forces but not within members coming from non-endemic areas.

What is important is our demonstration of an increase in antibody titres upon immunization although, as we and others have found in the past few months, there is no correlation between antibody titres and protection. It is worth adding that in all cases our original volunteers had a negative peripheral blood mononuclear cell stimulation index when tested with schizont sonicates before immunization, further indicating that the volunteers had never been in contact with malaria.

With regard to the question of different vaccination schedules for the two proteins, I cannot agree that it is possible to distinguish whether two doses are better than three from the data we present.

The cross-reactivity mentioned by Wasserman could be accounted for by the NANP sequence in both peptides rather than the linker peptide; in any case, as already mentioned, protection does not seem to be correlated with humoral and cellular responses.

Finally, as stated in our paper, we used the much more sensitive acridine orange method rather than Giemsa to test parasitaemia. During the challenge we employed the test every 12 hours, and every 4 hours on critical days, so that the volunteers would never be at excessive risk.

Manuel Elkin Patarroyo

Immunology Institute,

Hospital San Juan de Dios,

Bogota, Colombia

1. Patarroyo, M. E. et al. Nature 332, 158-161 (1988).

2. Espinal. C. A. \& Morales. P. O. Trans. R. Soc. trop. Med. Hyg. 78, 645-647 (1984)

\section{Whale size quandary}

SIR-One cannot easily accept Downhower and Blumer's penultimate statement ${ }^{1}$ that "if an aquatic neonate is smaller than this lower limit, then it cannot generate metabolic heat fast enough to compensate for heat loss" without qualification. One of the reasons that a large whale has such a low basic metabolic rate is that the circulation time of its blood volume is many minutes, making the delivery rate of nutrients to its cells a slow process ${ }^{2.3}$. The smaller neonatal whale will have a much shorter blood volume circulation time, a higher basic metabolic rate, and a cardiovascular system that could be physically capable of increasing delivery rate to a greater extent than is possible in the adult ${ }^{4}$.

Provided nutrient availability to the neonate itself does not become limiting, there seems no reason to suppose that it could not compensate for heat loss by increased metabolic activity. This, however, is unlikely to be achieved without affecting growth rate, which is the other serious drain on resources in early life. Size at birth presumably represents a workable compromise between the 'demands' of the two competing processes of heat production and growth, and the latter cannot be ignored.

Denys Wheatley

Department of Pathology,

University of Aberdeen,

Aberdeen AB9 2ZD, UK

I. Downhower, J.F. \& Blumer. L.S. Nature 335, 675 (1988)

Coulson. R.A. Hernandez. T. \& Herbert, J.D. Comp. Biochem. Physiol. 56A. 251 (1977)

3. Coulson. R.A. Perspect. Biol. Med. 27. 121 (1983).

4. Coulson. R.A. Comp. Biochem. Physiol. 84A. 217 (1986). 